\title{
From informed consent to shared decision-making
}

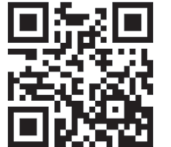

'Every human being of adult years and sound mind has a right to determine what shall be done with his own body. ${ }^{[1]}$

Morality in medicine was long dominated by paternalism: the belief that you could do almost anything to a patient as long as the principles of beneficence (best interests) and non-maleficence (no harm) were upheld. ${ }^{[2]}$ Kant and Mill reflected on autonomy and self-determination in philosophy, but it is only a century ago that the concept of informed consent, a strong expression of autonomy, was introduced into the law in the New York judgment quoted above. ${ }^{[1]}$

Respect for autonomy and self-determination was introduced into South African (SA) law in 1967 in Richter and Another v Estate Hammann $^{[3]}$ and subsequently secured in Castell v De Greef ${ }^{[4]}$ in $1994 .{ }^{[5]}$ The SA Constitution ${ }^{[6]}$ reflects the importance of an individual's rights and the right for patient self-determination, and the doctrine of informed consent was codified in sections 6,7 and 8 of the National Health Act. ${ }^{[7]}$ The Act provides for the patient's right to self-determination and the requirement for informed consent, and sets out the nature and scope of the information that should be disclosed. The disclosure should be done in a language the patient understands, and the patient's literacy level should be taken into consideration. ${ }^{[7]}$

While the law sets out the minimum requirements of informed consent, shared decision-making places the patient at the centre of care and may be seen as the pinnacle of patient-centred care. ${ }^{[8,9]}$

Shared decision-making is an approach whereby doctors and patients make decisions together using the best available evidence. Patient autonomy is respected. Patients can engage with the healthcare process, as they are encouraged to consider the options available to treat or manage their condition (and the likely benefits and harms of each) so that they can communicate their preferences and help select the best course of action. ${ }^{[10]}$

Shared decision-making has become more prominent partly because there is an ethical imperative to involve patients properly in decisions about their care, and partly because there is increasing evidence that this approach has benefits. ${ }^{[10]}$ There has been a shift in patient attitudes - the doctor no longer 'knows best'. Instead, patients have - and rightly - come to expect that 'no decision is made about me, without me. (This phrase has been widely used in the literature for some years, but its origin is obscure. It is used frequently as a catchphrase, encapsulating the basic tenet of shared decision-making, for example in the title of a UK Department of Health response ${ }^{[11]}$ to a White Paper entitled 'Equity and Excellence: Liberating the NHS') Table 1 illustrates the shift in attitudes from paternalism to shared decision-making.

A recent study by Politi et al. ${ }^{[12]}$ concluded that 'We should not assume that certain groups of patients don't want to or can't participate in decisions about their healthcare.' We should assume that all patients want to be involved, unless they specifically give a contrary signal, for example 'Whatever you think, doctor. Even then, the doctor needs to understand that a patient's asking that the doctor make the decision is a decision in itself. Should an adverse outcome occur, a patient may then claim that s/he had wished to be more involved in the decision-making, which emphasises the importance of documenting the decision-making process.

For shared decision-making to work, a joint approach is needed where listening and sharing information takes centre stage. Doctors cannot possibly know everything about a patient's value system, their beliefs, or their fears - all of which may influence their treatment decisions. Equally, patients cannot possibly know all the medical options available. Gawande ${ }^{[13]}$ suggests that in the 'arsenal' that is now available to treat over 13000 possible diagnoses, there are approximately 6000 drugs and 4000 possible procedures. This has substantially increased the complexity of decision-making for doctors. As a result, patient preferences are often also misdiagnosed. ${ }^{[14]}$

Certain information should be shared with all patients, for example, the treatment proposed and possible side-effects and complications. This is the case even if a patient asks that the doctor ultimately make the decision about treatment. Other information might be added because it is especially pertinent to a particular patient, e.g. in the light of their past medical or present social and occupational history. Good medical practice requires the doctor to check that the patient has understood the information provided and has been offered an opportunity to seek clarification. It is therefore not enough to just 'transmit' information - it is necessary to check whether the patient has both received it and absorbed it. This is especially pertinent in SA, where there are eleven official languages and use of an interpreter is required where a language barrier exists.

Respect for patients' autonomy extends to accepting their right to make their own decisions. Even if the practitioner does not believe that the decision is in a patient's best interests, provided it is reached after full consideration of the available options and is therefore an informed decision, the patient is entitled to fulfil his/her right to self-determination.

Some core principles are relevant:

- While patients can decline and request treatment, they cannot demand treatment.

- While doctors can suggest treatment, they cannot impose treatment.

- In the absence of an emergency, doctors can choose not to treat a patient.

What does the above mean in practice?

A number of models outline the steps required for the shared decision-making process to be valid. For example, Professor Glyn Elwyn and his colleagues recommend three main stages in the

Table 1. The shift in attitudes from paternalism to shared decision-making

Doctor's orders (paternalistic approach): The doctor tells the patient what is needed. This satisfies passive patients.

Prescriptive doctor - passive patient

Patient's choice: Informative doctor -

The doctor simply provides information about the pros and cons of the various options available active patient for treatment, but gives no recommendation. This satisfies the active, assertive patient.

Shared decision-making

An interactive process occurs that begins with engagement between doctor and patient and ends with a decision jointly made, or with which both doctor and patient are comfortable. 


\section{EDITORIAL}

discussion - Choice Talk, Options Talk and Decision Talk - with multiple steps in each stage..$^{[15]}$ That model, and most of the others suggested in the literature, include the following as components of the doctor's role in the shared decision-making process:

- Listening. Most patients you see have an idea about what is wrong with them and what treatment they anticipate you will provide. It is generally recommended that the patient's views be elicited first, and that the doctor seeks to understand what the patient already knows, what is important to them and what their expectations of treatment are.

- Informing. Only then should the doctor add his/her own views, based on a clinical assessment, as well as such information as is necessary to add to - or correct - the patient's existing knowledge.

- Discussing. Having established the patient's expectations at the start, the next step is to discuss the diagnosis and treatment options and address the patient's expectations - even if this means explaining gently why they cannot be met. The benefits and risks of the various options available should be addressed, as set out in section 6 of the National Health Act. ${ }^{[7]}$ This includes the option, and possible consequences, of no treatment. Clinical decision support tools can be very helpful, for example the 'Option Grid. ${ }^{[16]}$ Preprepared option grids on a number of common topics are available for open use on the Option Grid website. ${ }^{[16]}$

- Deciding. As the discussion proceeds, the range of options will narrow as the doctor or the patient expresses a reluctance to proceed with some. This will usually lead to one preferred, and mutually agreed, decision. If more than one option is still on the table, either the doctor will say to the patient, 'Well, we both seem to be happy with either [option A and B], so which would you prefer?' or the patient will say 'I'm comfortable with either of those, so whichever you think, doctor.' Any recommendation made should take into account the preferences, values and expectations of the patient. It is important to check the patient's understanding of the options available, the risks involved and the consequences of the decision made. If agreement cannot be reached, it may be advisable to obtain a second opinion or otherwise stop the process.

- Documenting. It is essential to document the key elements of the above discussion in the patient's notes, including details of options and risks. The note does not have to be voluminous, but it must be more than 'Agreed - lap choly. Risks discussed.' Ask yourself: 'If other doctors read these notes, will they know what we discussed and how we came to agree on what is to happen next?'

There is now a voluminous literature about shared decision-making. Two websites in particular are well worth studying, one from the $\mathrm{UK}^{[17]}$ and one from the USA. ${ }^{[18]}$ Another excellent reference, from the Kings Fund, is 'Making shared decision making a reality: No decision about me, without me. ${ }^{\text {[19] }}$

Shared decision-making is an extension of the informed consent process. It has to engage the patient to be meaningful. If we just set out to meet the requirements for 'informed consent', we risk seeing each patient only as a clinical problem - a disorder of anatomy or physiology to be diagnosed and treated. But each patient brings their own personality, experience, knowledge, and indeed 'baggage' to the clinical encounter. If we do not allow them to bring these elements to a discussion about treatment options, we do them a disservice.

'We must not see any person as an abstraction. Instead, we must see in every person a universe with its own secrets, with its own sources of anguish, and with some measure of triumph. ${ }^{\text {[20] }}$

\section{Howard Manyonga}

Medical Protection Society Educational Workshop Faculty Member and Wits Reproductive Health and HIV Institute, Johannesburg, South Africa

\section{Graham Howarth}

Head of Medical Services in Africa, Medical Protection Society, Victoria House, 2 Victoria Place, Leeds, UK

\section{Mark Dinwoodie}

Head of Member Education, Medical Protection Society, Victoria House, 2 Victoria Place, Leeds, UK

\section{Paul Nisselle}

Senior Consultant, Educational Services, Medical Protection Society, Victoria House, 2 Victoria Place, Leeds, UK

\section{Sarah Whitehouse}

Senior Writer and Editor, Medical Protection Society, Victoria House, 2 Victoria Place, Leeds, UK

Corresponding author: G Howarth (graham.howarth@mps.org.uk)

1. Schloendorff v Society of New York Hospital 1914, 211 NY 125, 105 N.E. 92. 2. Dhai A. Informed consent - 2008. South African Journal of Bioethics and Law 2008;1(1):28-30. http:// www.sajbl.org.za/index.php/saibl/article/view/5/9

Richter and Another v Estate Hammann 1967, (3) SA 226 (C).

4. Castell v De Greef 1994, (4) SA 408 (C).

5. Britz R, Le Roux-Kemp A. Voluntary informed consent and good clinical practice for clinical research in South Africa: Ethical and legal perspectives. S Afr Med J 2012;102(9):746-748. [http://dx.doi.org/10.7196/ SAMJ.5498]

6. South African Government. The Constitution of the Republic of South Africa 1996. Pretoria: Government Printer, 1996. www.thehda.co.za/uploads/images/unpan005172.pdf (accessed 15 April 2014).

7. National Health Act 61 of 2003. http://www.saflii.org/za/legis/consol_act/nha2003147/(accessed 7 July 2014). 8. Stiggelbout AM, Van der Weijden T, De Wit MPT. Shared decision making: Really putting patients at the centre of healthcare. BMJ 2012;344:e256. [http://dx.doi.org/10.1136/bmi.e256]

9. Barry MI, Edgman-Levitan S. Shared decision making - the pinnacle of patient-centered care. N Engl Med 2012;366(9):780-781. [http://dx.doi.org/10.1056/NEJMp1109283]

10. Elwyn G, Laitner S, Coulter A, Walker E, Watson P, Thomson R. Implementing shared decision makin in the NHS. BMI 2010;341:c5146. [http://dx.doi.org/10.1136/bmj.c5146]

in the NHS. BMT 2010;341:c5146. [http://dx.doi.org/10.1136/bmj.c5146]
1. NHS. Liberating the NHS: Nothing about me, without me. https://www.gov.uk/government/uploads/ system/uploads/attachment_data/file/216980/Liberating-the-NHS-No-decision-about-me-without-meGovernment-response.pdf (accessed 7 July 2014).

12. Politi MC, Dizon DS, Frosch DL, Kuzemchak D, Stiggelbout AM. Importance of clarifying patients desired role in shared decision making to match their level of engagement with their preferences. BM] 2013;2:347:f7066. [http://dx.doi.org/10.1136/bmj.f7066]

13. Gawande A. The Checklist Manifesto: How to Get Things Right. New York: Metropolitan Books, 2009.

14. Mulley A, Trimble C, Elwyn G. Stop the silent misdiagnosis: Patients' preferences matter. BM] 2012;345:e6572. [http://dx.doi.org/10.1136/bmi.e6572]

5. Elwyn G, Frosch D, Thomson R, et al. Shared decision making: A model for clinical practice. J Gen Intern Med 2012;27(10):1361-1367. [http://dx.doi.org/10.1007/s11606-012-2077-6]

16. Option Grid Collaborative. http:///www.optiongrid.org (accessed 19 March 2014).

17. The Health Foundation. http://shareddecisionmaking.health.org.uk/basics-of-shared-decision-making/ (accessed 19 March 2014).

18. Informed Medical Decisions Foundation. http://www.informedmedicaldecisions.org (accessed 19 March 2014)

19. Coulter A, Collins A. Making shared decision making a reality: No decision about me, without me. 2011. http: www.kingsfund.org.uk/publications/making-shared-decision-making-reality (accessed 19 March 2014).

20. Skoot R. The Immortal Life of Henrietta Lacks. New York: Crown, 2010.

S Afr Med J 2014;104(8):561-562. DOI:10.7196/SAMJ.8287 